\title{
A SOCIOLOGIA: CIÊNCIA E OFÍCIO
}

\author{
LUCIE TANGUY*
}

RESUMO: A autora analisa aqui os principais aspectos da evolução do ofício de sociólogo. Para tanto, parte da sua experiência em sociologia nas fronteiras da educação e do trabalho e da revisão de um vasto corpus de arquivos oriundos de diversas fontes. Reconstitui, assim, a história da sociologia do trabalho na França dos anos de 1950 aos anos de 1990, graças a um esquema de análise que também poderia ser transposto para a sociologia da educação. Recoloca essa história no seu contexto social e intelectual, retraça as ações dos pesquisadores para definir teorias, torná-las reconhecidas, e assim informar normas de cientificidade às gerações seguintes. Examina algumas indagações sobre o ofício de sociólogo: como conjugar autonomia de pensamento e engajamento na sociedade no seu momento histórico? A figura do sociólogo intelectual dos anos de 1950-1960 estaria sendo substituída pelo papel de consultor (expert)?

Palavras-chave: Sociologia da ciência. Trabalho. Teorias. Métodos. Perícia.

\section{SOCIOLOGY: SCIENCE AND JOB}

ABSTRACT: The author analyses the main aspects of the evolution of the sociologist profession. She does it on the ground of her experience in a sociology located between education and work and on the inventory of a very important corpus of archives from different sources. She rebuilds the history of the sociology of work in France from the 1950s to the 1990s with an analytic schema that could also be used by the sociology of education. She puts that history in its social and intellectual context. She recalls the scientists' actions to define theories, get them recognised and impose scientificity norms for the new generations. She also looks into a set of questions about the sociologist profession: how can one combine autonomy of thought and involvement in their own society? Will the expert image take over of intellectual, specific of the 1950-1960s?

Key words: Sociology of science. Work. Theories. Methods. Expertise.

* Diretora de pesquisa no Centre National de la Recherche Scientifique (CNRS - Centro Nacional da Pesquisa Científica), laboratório Gênero, Trabalho, Mobilidades, da Universidade Paris X - Nanterre. E-mail:1tanguy2@gmail.com

Tradução de Alain François, revista por Carolina Violante Peres. Revisão técnica de Liliana Segnini. 


\section{LA SOCIOLOGIE: SCIENCE ET METIER}

RÉSUMÉ: L'auteure analyse ici les aspects majeurs de l'évolution du métier de sociologue. Elle le fait à partir de son expérience en sociologie aux frontières de l'éducation et du travail et du dépouillement d'un vaste corpus d'archives de sources différentes. Elle reconstitue ainsi l'histoire de la sociologie du travail en France des années 1950 aux années 1990 à l'aide d'un schéma d'analyse qui pourrait également être transposé à la sociologie de l'éducation. Elle replace cette histoire dans son contexte social et intellectuel, retrace les actions des chercheurs pour définir des théories, les faire reconnaître, et faire admettre des normes de scientificité à destination des générations suivantes. Elle examine ainsi un ensemble de questions sur le métier de sociologue: comment conjuguer autonomie de la pensée et engagement dans la société de son temps? La figure du sociologue intellectuel des années 1950-1960 est-elle en train de laisser sa place à celle de l'expert?

Mots-clefs: Sociologie de la science. Travail. Théories. Méthodes. Expertise.

\section{Introdução ${ }^{1}$}

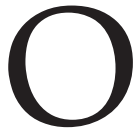

s sociólogos não costumam elaborar uma análise reflexiva a propósito de seus próprios trabalhos, embora esta seja inerente à atividade de suas pesquisas. Eu tentei implementar essa exigência em algumas oportunidades: no início dos anos de 1990, após uma missão para o Ministério da Educação nacional sobre o ensino profissional na França (Tanguy, 1995), para o quadragésimo aniversário da revista Sociologie du Travail (Tanguy, 2001) e, hoje, num livro que busca observar e analisar o trabalho dos próprios sociólogos, no qual este artigo se inspira amplamente (Tanguy, 2011).

Para mim, não se trata de dar, mas de tirar lições de uma experiência de pesquisa após quarenta anos de sua realização. Sempre afirmei o meu pertencimento a uma sociologia crítica que cabe definir, pois costuma ser compreendida como uma denúncia da ordem existente. Antes, porém, vou lembrar como fui levada a construir esta postura intelectual, a empreender este trabalho de volta sobre o meu próprio percurso intelectual e a me interessar mais particularmente pela sociologia do trabalho. Isso talvez se deva ao fato de eu ter ingressado na sociologia baseada numa crença: o conhecimento do mundo social contribui para transformá-lo. Além do mais, para mim, como para muitos aprendizes sociólogos de minha geração, o caráter central do trabalho na constituição das relações sociais era um postulado da sociologia.

Entretanto, enquanto escrevia o meu último livro, cheguei a duvidar da minha legitimidade para tanto. Não pertenço ao núcleo dos sociólogos do trabalho oficiais. Passei a maior parte do meu tempo de pesquisa a estudar objetos que se situam na fronteira de esferas institucionalmente separadas: educação e trabalho, 
ensino profissional, aprendizagem, formação permanente, que são deixados de lado pelos sociólogos da educação e do trabalho. Essa posição de investigadora inscrita nas fronteiras me obrigou a raciocinar em termos de relações mais do que em termos de campos. Também me levou a refletir sobre as categorias com as quais se pensa, pois compreendo que nunca foram evidentes.

Então, por que a sociologia do trabalho, e não a sociologia da educação, por exemplo?

Porque me aproximara da sociologia do trabalho e esta se apresentou como a matriz da sociologia na França nas duas décadas após a Segunda Guerra Mundial, período no qual a sociologia renasceu naquele país, graças a autores como Friedmann, Naville, Touraine, Crozier, Reynaud, entre outros, como mostrou J.-M. Chapoulie (1991).

Contudo, o esquema de análise que implementei para reconstituir a história da sociologia do trabalho na França, dos anos de 1950 aos anos de 1990, que vou delinear aqui, apresenta, acredito, um caráter bastante geral que permite a sua transposição a outros ramos da sociologia, não só exclusivamente a do trabalho. O subtítulo do livro deixa isso bem claro: "Investigação sobre o trabalho dos sociólogos".

Eu vejo meu papel nessa pesquisa como a de um "passeur", no sentido que adquire esta palavra nos esportes coletivos, ou seja, aquele que passa a bola para outro jogador da mesma equipe mais bem colocado para fazer um gol ou atingir o objetivo daquele esporte (Cheng, 2008). Logo, a intenção é transmitir as lições de uma experiência de pesquisa vivida no decorrer de parte do período em questão. Como disse, filio-me a uma sociologia crítica, e vou logo dizer o que entendo por isso. $\mathrm{O}$ primeiro mal-entendido que se deve dissipar é o que consiste em pensar que o papel do sociólogo crítico se confunde com uma obsessão de contestação radical e geral do pensamento. Costuma-se ensinar aos futuros sociólogos que eles devem dissociar os posicionamentos explicitamente políticos do trabalho propriamente intelectual. $\mathrm{Na}$ prática, as coisas são bem mais complexas. Senti isso na pele em diversas oportunidades e vou lembrar duas delas que ilustram como o sociólogo tenta conciliar duas séries de exigências que estão em tensão.

A primeira experiência que vou evocar marcou meu itinerário intelectual porque me obrigou a refletir sobre as indagações que colocamos a partir de um objeto: as dos tomadores de decisões ou, mais geralmente, as dos diversos protagonistas que se enfrentam numa situação problemática. De fato, a concepção e a elaboração de uma obra coletiva que organizei (Tanguy, 1986) me mostraram o quanto o investigador em ciências sociais precisa refletir sobre as ferramentas com as quais pensa, e em primeiro lugar, examinar as palavras e noções que usa, pois participam da constituição da realidade social (Hughes, 1996). A posteriori, percebi que, pela maneira 
como analisava um questionamento social, essa obra tinha contribuído para dar forma a representações e políticas que buscavam estabelecer relações entre duas ordens de fenômenos, a formação e o emprego, relações que surgiam como necessárias, ao passo que o objetivo da obra era o contrário. Em suma, muitos aspectos dessa obra conseguiram justificar a propensão a falar de "relação formação/emprego" no singular e a substantivar fenômenos que não podem ser pensados senão em termos de processo. A maioria dos estudos nesse campo, hoje, enfatiza a formação como a condição primeira de acesso ao emprego, ocultando as relações sociais que presidem às relações entre diplomas e postos de trabalho. Excetuando as diferenças de sexo, que são levadas em conta - talvez por serem mais facilmente mensuráveis, mas, sobretudo, porque os movimentos feministas fizeram com que sejam reconhecidas como fato social -, as desigualdades sociais parecem, atualmente, resultar das desigualdades escolares, agora chamadas de desigualdades de formação (Tanguy, 2007).

A segunda experiência que me levou a refletir sobre as responsabilidades sociais do sociólogo data de 1991, momento em que uma missão me foi confiada pelo Secrétariat de l'Enseignement Technique et Professionnel (Secretariado do Ensino Técnico e Profissional) para examinar os problemas levantados pela palavra de ordem promovida pelo Ministério da Educação nacional: "80\%" de uma faixa etária no nível baccalauréat, o que acentuava a desvalorização do ensino profissional e invalidava o CAP, diploma que certificava a qualificação operária, o qual se tornava um diploma dito de "empregabilidade". O debate público suscitado por esse relatório (que não interessou, de modo algum, os universitários) obrigou-me a examinar a tarefa do sociólogo que, embora tome o presente por objeto, deve considerá-lo um caso particular num universo de possibilidades. Se todos concordam em dizer que a tarefa do sociólogo consiste em dar conta do real, não há necessariamente acordo para afirmar que o real, como disse G. Granger (1995), compreende também o não atual, os possíveis que foram descartados. De modo que a compreensão de fatos atualizados supõe confrontá-los às possibilidades contidas nas situações observadas. Assim, senti concretamente o que Pierre Bourdieu (2001) falou e repetiu: não há sociologia de um fato contemporâneo se não se faz a sua genealogia. Assim entendida, uma sociologia crítica é sempre uma sociologia do possível e não a de uma necessidade (Elias, 1991, cap. 6).

Esse ponto de vista me levou a fazer uma análise sócio-histórica do campo de atividades chamado "formação", em colaboração com colegas sociólogos, historiadores e juristas, durante quase cinco décadas na França, para examinar como, pelas diversas propriedades que lhe foram atribuídas, impôs-se como um instrumento de mudança de interesse geral. De fato, a formação é representada como um bem universal procurado tanto pelo Estado e pelas empresas quanto pelos assalariados.

Minha prática da sociologia permitiu-me avaliar as tensões que existiam entre as diversas exigências subjacentes à atividade científica. Vou lembrar duas delas: 
submeter-se aos imperativos da argumentação científica e prever as consequências sociais e políticas das suas análises; e apoderar-se dos problemas do seu tempo e produzir conhecimentos que se integram num corpus disciplinar.

O exercício que consiste em examinar as pesquisas realizadas e seus resultados constitui, portanto, uma precondição à afirmação de toda perspectiva sociológica porque, para retomar mais uma fórmula de Pierre Bourdieu: "A sociologia da sociologia é uma das condições primeiras de uma sociologia científica" (Bourdieu, 1984, p. 22). Essa atitude não condena a pesquisa científica ao relativismo, apenas coloca as condições para um conhecimento crítico dos limites do conhecimento, que é a condição do conhecimento científico.

\section{Um procedimento sócio-histórico}

Lembrei as condições sociais e políticas nas quais o trabalho foi definido como um campo próprio da sociologia, distinto dos campos reconhecidos antes da Segunda Guerra Mundial e, além do mais, erigido, como disse, em "matriz dos fatos sociais". Neste sentido, examinei o estado da sociologia do trabalho dos anos de 1950 aos anos de 1990, os lugares onde se construiu, os pesquisadores que a ela se filiaram e os meios que mobilizaram para tanto.

O quadro que delineei baseia-se, essencialmente, em arquivos oriundos de diferentes fontes: as do Ministério do Trabalho (nunca consultadas até então), para os anos de 1950-1960; os relatórios de conjuntura e de atividades do Centro Nacional da Pesquisa Científica (Centre National de la Recherche Scientifique - CNRS), os relatórios de atividades de pesquisadores classificados como sociólogos do trabalho e os arquivos não classificados da Sociedade Francesa de Sociologia (SFS), para os anos de 1950-1970; e, para os anos de 1980-1990, os arquivos do Programa Interdisciplinar de Pesquisas Tecnologia, Trabalho, Emprego e Modos de Vida (Programme Interdisciplinaire de Recherches Technologie, Travail, Emploi et Modes de Vie - Pirttem), o qual, em razão das verbas que lhes foram destinadas e da sua duração (quase dez anos), conseguiu a adesão de laboratórios e pesquisadores especializados nesse campo.

Os dados assim coletados foram comparados às entrevistas com atores científicos da época: pesquisadores, mas também agentes da administração das políticas de pesquisa. Também pesquisei as revistas: Sociologie du Travail e Revue Française de Sociologie e, de modo menos sistemático, os Cahiers Internationaux de Sociologie e o Année Sociologique, desde sua republicação depois da guerra até os anos de 1960.

Inspirei-me no esquema de análise desenvolvido por J.-M. Chapoulie no seu estudo sobre a tradição sociológica de Chicago (Chapoulie, 2001) e de uma corrente 
de pesquisas construída pelos historiadores das ciências, mais conhecida nos países anglo-saxônicos do que na França, e mais aplicada às ciências da natureza do que às ciências sociais, os "sciences studies" (Pestre, 2006), que pretendem corrigir uma representação ideal da ciência, ao deslocar o seu modo de análise dos textos e seus autores para a produção das teorias e da pesquisa em ato. Assim, a uma história linear, feita de enunciados gerais e universais, opõem uma história descontínua e contextualizada que relativiza as teorias e suas genealogias, anteriormente consideradas irrefutáveis.

Sempre preferi os fatos aos discursos, as práticas aos enunciados gerais, o método indutivo às teorias abstratas. Logo, ao seguir esse raciocínio, tentei reunir um grande número de informações a respeito das políticas de pesquisa, das instâncias de representação e regulação das comunidades de pesquisadores, das correntes de pesquisa consideradas dominantes num dado momento, das lutas travadas pelos seus autores para serem reconhecidos, assim como das práticas das próprias pesquisas e, singularmente, dos métodos reivindicados como científicos.

Insistirei nesse último ponto: esse procedimento me permitiu ressaltar as correspondências entre os problemas colocados pelas políticas e o estilo de pesquisa erigido em norma em diferentes momentos (Hacking, 2003). Os objetos, assim como as formas de pesquisa privilegiadas pelas ciências sociais, costumam vincular-se ao movimento de transformações apresentadas, num dado momento, como necessárias e de interesse geral e designado pelo termo "modernização". Essa noção é geralmente emprestada das políticas públicas, em momentos particulares nos quais reformas estão sendo promovidas no intuito de introduzir mudanças maiores na ordem social. Examinei como os sociólogos se situaram em relação a essa questão em dois momentos diferentes na França: nos anos de 1960 e 1980.

\section{A modernização da França no período de 1950-1960 e a adoção de uma sociologia empírica como norma}

A adoção de uma sociologia empírica na França ocorreu num contexto análogo àquele em que o modelo de ciências sociais havia nascido nos Estados-Unidos três décadas antes: a cooperação entre pesquisadores em ciências sociais e as elites para orientar políticas sociais, a do New Deal em particular (Pollack, 1979). Aconteceu num período marcado por um conjunto de dimensões históricas favoráveis: a institucionalização das políticas para a ciência, a assimilação desta com o "interesse nacional", a aliança e a cooperação, no mais alto escalão, do poder político e da comunidade científica (Rouban, 1988, p. 146). A confiança política na ciência traduziu-se por um aumento das verbas que lhe foram destinadas, e também pela sua inscrição nessa empreitada de projeção do desenvolvimento econômico e social da França que esse plano constituía (Tanguy, 2002). 
De fato, instituída logo após a guerra, a planificação apresentava-se não somente como um instrumento de reconstrução de uma economia destruída pela guerra, mas também como uma grande tarefa coletiva de desenvolvimento econômico e de modernização da sociedade francesa. Primeiro, a modernização foi compreendida como exigência de crescimento e intensificação da produtividade econômica e, em seguida, foi pré-condição para a construção de um futuro, marcado pela aceleração do tempo que traz o progresso, e no qual o homem se torna mestre da sua história.

Nos anos de 1950, o papel do Ministério do Trabalho foi decisivo em termos de políticas de pesquisas sobre o trabalho. Ex-dirigente sindicalista cristão, o ministro impulsionou um conjunto de reformas oriundas do programa do Conseil National de la Résistance (Conselho Nacional da Resistência), como as leis sobre a previdência social, por exemplo. Criou o Institut des Sciences Sociales du Travail (Instituto das Ciências Sociais do Trabalho), onde ocorreram as primeiras pesquisas empíricas no âmbito do Plano Marshall (plano de auxílio americano para reconstruir países europeus cuja economia havia sido devastada pela guerra).

Nos anos de 1960, sociólogos de primeira linha engajaram-se em todo tipo de ações para fazer reconhecer a sua disciplina como uma ciência que fornece explicações e predições, e pode prever as tendências do futuro e repelir a incerteza de modo a possibilitar condições para o advento de uma sociedade "moderna" cuja aceitação, por sua vez, era indeterminada. Não hesitaram em justificar suas ações e seus interesses em nome de uma demanda que lhes era proposta, ao passo que, na realidade, ofereciam as suas investigações empíricas às administrações estatais e, em primeiro lugar, aos planejadores. Universitários e altos funcionários partilhavam vontade e conviçcão: mobilizar conhecimentos para agir racionalmente sobre o mundo social.

Portanto, nos anos de 1950-1960, esses sociólogos definiram uma forma de raciocínio científico que opunha a "objetividade", atributo maior das ciências modernas, à subjetividade (Daston \& Galison, 2009, p. 431-434). Pleitearam em favor de uma pesquisa organizada em laboratórios reunindo condições para observar e medir fenômenos sociais em grande escala. $\mathrm{O}$ apego por uma sociologia quantitativa embasada nesse tipo de raciocínio encontrou, nesses anos, condições favoráveis à sua consagração. Essa sociologia foi, de saída, apresentada pelos seus promotores como a disciplina mais apropriada para o estudo dos problemas sociais do presente imediato e, mais geralmente, para o estudo da mudança, imperativo econômico e político posto pelos tomadores de decisões nos anos de 1960. Conseguiu impor-se num contexto em que o desenvolvimento técnico-econômico e a fé no progresso eram valores-chave. 


\section{Deslocamento de uma sociologia do trabalho para uma sociologia da empresa, nos anos de 1980-1990}

O segundo caso de relação entre política de modernização e orientação das pesquisas na sociologia do trabalho situa-se nos anos de 1980-1990, momento em que o governo de esquerda impulsionou uma política industrial no cerne da qual colocou a pesquisa, as inovações e a renovação das empresas.

Os objetivos políticos de modernização das empresas e a definição de programas de pesquisa vão convergir graças à mobilização de pesquisadores empreendedores que compreenderam, naquele momento, a possibilidade de dar conta de certas mudanças vigentes e, a partir daí, de afirmar a necessidade de romper com os pontos de vista admitidos anteriormente. Assim, a sociologia do trabalho, que era uma sociologia das sociedades industriais, passou a ser uma sociologia de fábricas.

Essa convergência de pontos de vista de homens políticos e de pesquisadores, que, na verdade, perseguiam objetivos diferentes, vai dar lugar a uma inflexão notável das representações: a empresa é considerada o lugar central a partir do qual se pode observar e analisar as transformações de um sistema socioeconômico no seu conjunto. Essa tese implementará um programa interdisciplinar no qual novas disciplinas, como as ciências da gestão, foram incluídas ao lado de disciplinas sem vínculo, até então, com as ciências sociais, como as ciências da vida e das engenharias.

A interdisciplinaridade foi inscrita no cerne desse vasto programa de pesquisas, o Pirttem, sem equivalente na história do CNRS em termos de ciências sociais. Essa interdisciplinaridade continha em si um modo de produção de conhecimentos que somava profissionais da pesquisa e experts. Os administradores da pesquisa, os responsáveis pelos novos dispositivos de pesquisa foram, nos anos de 1980-1990, os agentes que implementaram essas mudanças nas ciências sociais.

No mesmo programa, contratos de conhecimento foram firmados com empresas públicas e organizações sindicais, nos quais pesquisadores e executivos de empresas colaboravam para estudar problemas sociais específicos a cada empresa e, por um deslocamento "natural", para examinar as respostas que deviam ser dadas.

As fórmulas de interdisciplinaridade e os contratos de conhecimento são característicos do novo regime de produção de conhecimento no qual pesquisadores e atores sociais são considerados parceiros providos de igual capacidade, embora cada qual ao seu modo, para produzir conhecimentos em dadas situações em que convenções definem o papel de cada um e a sua confrontação.

A sociologia do trabalho surgiu como ideal para constituir o cerne dessa interdisciplinaridade em razão da sua abertura para as outras disciplinas das ciências 
sociais e pela ausência de uma única doutrina forte, mas também porque já mostrara as relações de interdependência que existiam entre as organizações sociais do trabalho e as mudanças técnicas.

Os dispositivos e programas de pesquisa instaurados marcaram profundamente as práticas dos pesquisadores que estavam envolvidos neles e, mais amplamente, contribuíram para redefinir o ofício de investigador em ciências sociais. As fronteiras entre pesquisa e conhecimento especializado, anteriormente proclamadas estanques, acabaram se dissipando. A missão do investigador, que é a de produzir conhecimentos, passou a incluir a de intervir, ao lado de outras categorias de atores, para mudar a situação problemática. O pesquisador tende, então, a ser apresentado e a se apresentar como um "agente de mudança". Embora muitos tenham aderido a essa nova visão da pesquisa, ao poder atribuído aos conhecimentos para transformar a empresa, parte da comunidade dos sociólogos do trabalho resistiu. Mesmo assim, uma corrente da sociologia da empresa desenvolveu-se com as escolas de comércio e publicou manuais, entre os quais aquele publicado na coleção Repères, muito apreciada pelos estudantes (Thuderoz, 1996).

Na prática, a afirmação de uma corrente de pesquisa centrada na empresa foi facilitada pelo fato de que ela possibilita análises interdisciplinares, carro-chefe das políticas de pesquisa dos anos de 1980. A economia industrial tanto quanto a história social, o direito do trabalho, as ciências da gestão, as ciências cognitivas e a ergonomia são disciplinas que podem convergir e se firmar no estudo das empresas. $\mathrm{O}$ fato de se constituir numa encruzilhada ajudou a sua ascensão nas ciências sociais.

Mais do que outras, a sociologia da empresa participou de um ponto de vista performativo que se livrou desse imperativo de distanciamento tradicionalmente vinculado ao ofício de sociólogo. Essa corrente de pesquisas e os pontos de vista sociológicos, mas também ideológicos, que lhe são subjacentes se difundiram mais facilmente ainda porque criaram uma nova concepção do ofício de sociólogo que integrava a compreensão e a ação sobre o mundo social na qualidade de expert.

Portanto, no decorrer dos anos de 1980-1990, ocorreu uma guinada em direção não de uma sociologia crítica, mas da consultoria, a qual se intensificou nas décadas seguintes. À figura do sociólogo intelectual que prevaleceu nos anos de 1950-1960 sucedeu a do expert. Sua função de caçador de mitos foi substituída pela de organizador. $\mathrm{O}$ fato de pensarem a mudança sem observar o que não muda traduziu-se por uma perda de capacidade crítica das análises sociológicas realizadas.

A análise desenvolvida aqui mostra como, em certas condições sociais e políticas, surge uma nova corrente de pesquisa: pela confluência de ações oriundas dos principais protagonistas presentes e, em primeiro lugar, dos próprios pesquisadores. 


\section{Conclusão}

Ao término deste passeio pela história da sociologia do trabalho, pretendi revisar a narrativa convencional que a descreve nos manuais.

A análise dos fatos apresentados ao longo destas páginas enfatiza o caráter contextualizado das propostas enunciadas pelos sociólogos do trabalho que, geralmente, apenas são pertinentes quando localizadas no tempo e no espaço que estão na origem da sua construção. A variabilidade das temáticas e das perspectivas observadas em aproximadamente 40 anos mostra que objetos desaparecem do campo da sociologia do trabalho sem justificava. É o caso da questão dos salários, das carreiras profissionais (que não podem ser reduzidas a trajetórias, as quais são muito estudadas) ou ainda do Estado, que ocupavam um lugar de destaque nas temáticas escolhidas durante as duas primeiras décadas após a Segunda Guerra na França. Conceituar uma teoria que estabeleça relações estáveis entre certo número de fenômenos identificados empiricamente e replicáveis supõe, pelo menos, certa estabilidade dos objetos de pesquisa em termos de temáticas: condição que não é reunida na sociologia do trabalho, onde as temáticas se deslocam mais do que se reformulam. Afinal, o que os sociólogos do trabalho responderiam à questão colocada por G. Lenclud (2009) a respeito da antropologia? "Sabemos mais e melhor hoje do que ontem?" Sabemos provavelmente mais, mas será que sabemos melhor? Talvez sobre certas indagações, mas quais? Os modos de organização do trabalho, os conflitos, por exemplo? As descontinuidades opõemse à acumulação de conhecimentos que poderiam ser estabelecidos a respeito de uma classe de objetos empiricamente identificados, mas também a respeito dos modos de pesquisa, das concepções da prova, dos critérios de objetividade (Hacking, 2003). Vemos o quanto, na Sociologia, a busca por "paradigmas" não apenas é ilusória, nos muitos sentidos em que Kuhn usa este termo, inclusive no de "matriz disciplinar", mas constitui um obstáculo para toda forma de acumulação científica.

As décadas de 1980-1990, que viram o modelo da consultoria se alargar, comprovam também um rebaixamento das ambições científicas e das exigências de métodos. Ao se ampliar e ao se abrir para o meio dos profissionais da consultoria e dos estudos, o meio universitário respondeu de fato ao objetivo almejado pelas políticas e pelos programas: propor soluções para os seus problemas sociais.

Na própria opinião de historiadores, demógrafos e geógrafos, a Sociologia conseguiu influenciar essas disciplinas pela difusão dos métodos que elaborava. Desde os anos de 1950, foi escolhida pelo Ministério do Trabalho para lançar o seu programa de ciências sociais do trabalho. O seu caráter pluralista, que autoriza uma renovação quase permanente dos seus objetos e dos seus esquemas de análise, também faz dela um lugar de recomposição interdisciplinar, como salientava J.-C. Passeron (1982). Esteve no cerne de programas de pesquisa sobre o trabalho naquela 
época. Essa capacidade para integrar novos questionamentos é também inescapavelmente associada a uma maior permeabilidade às políticas da pesquisa.

Em relação às suas ambições arvoradas desde as suas origens, a Sociologia dá a impressão de que está em crise. Esse sentimento não é novo, antes, parece ser endêmico. Também não é próprio da sociologia francesa, uma vez que R. Collins (1986) observava, há vinte anos, as razões do mal-estar sentido pelos sociólogos nessa tendência "patológica" para uma especialização ampla demais, o que impede pôr em coerência cumulativa resultados e modos de pesquisa.

A História, disciplina fronteiriça da Sociologia, define-se de modo completamente diferente, distante do modelo das ciências da natureza que fascinou os sociólogos. No seu diálogo com Georges Gurvitch, F. Braudel (1958, p. 83-97) informava que a História não é uma disciplina com regras e métodos perfeitamente definidos de uma vez por todas. Acrescentava que "por história (em itálico no original) entendia uma pesquisa cientificamente conduzida, digamos até uma ciência, mas complexa. Não há uma história, uma profissão, mas ofícios, histórias, uma soma de curiosidades, de pontos de vista, de possibilidades, à qual outras possibilidades virão se acrescentar amanhã". É, portanto, no registro do ofício, do ofício de investigador, que esse famoso historiador define essa disciplina intelectual.

Assim como F. Braudel, J.-F. Revel (2009, p. 85-111) sustenta que "a história quer primeiro ser uma prática, renitente a todo e qualquer enquadramento teórico. Evidencia, na verdade, uma justaposição de práticas heterogêneas (...). Entretanto, uma forma de cumulação manifesta-se graças ao incessante trabalho crítico de aquisição e de confrontação de dados". Portanto, nas ciências sociais, a cumulação não pressupõe a existência de enquadramentos teóricos e muito menos a sua unificação.

Quis trazer uma contribuição para o exame de indagações fundamentais sobre a atividade científica na Sociologia, a partir de um ângulo de abordagem singular e, mais do que uma disciplina constituída, apresentar a sua constituição no seu contexto social e intelectual, as lutas que nela foram travadas para fazer triunfar tal perspectiva sobre outra. Essa contribuição continua aberta à crítica oriunda de outros pontos de vista. Caso ocorram, eu consegui assumir o papel de passeur ao qual me referi no início desta explanação, transferindo o debate para outros membros da equipe de sociólogos.

Gostaria de ter desenvolvido o mesmo tipo de raciocínio em torno de uma noção que está no cerne das relações salariais na França (e que interessa a muitos de vocês), a qualificação, para mostrar como foi inscrita no âmago das políticas escolares. Estas levam a crer que qualificação é determinada por um único fator, a formação, ao passo que se trata de uma relação social definida no mercado do trabalho, que escapa fortemente à escola (Naville, 1956). Colocar em equivalência o nível de 
formação e a qualificação foi uma proposta dos planificadores no âmbito da procura por maior produtividade. Os sociólogos aderiram a essa visão e transformaram a formação que, inicialmente, não passava de uma simples nomenclatura de prospectiva, de futuro, numa categoria de análise e de interpretação para dar conta de todo tipo de comportamento (o voto, por exemplo).

Por meu lado, analisei os pressupostos dessas políticas e os seus efeitos perversos: mascaram a divisão do trabalho, polarizam a hierarquia escolar e intensificam a seleção no mercado de trabalho (Tanguy, 1995, 2002). Um dos papéis de uma sociologia crítica é, a meu ver, contribuir para enfraquecer as hierarquias entre os princípios de hierarquização: entre o ensino geral, sempre associado ao universal, à cultura, e o ensino técnico, associado à falta dessas propriedades. Para tanto, é preciso romper com a teoria do conhecimento que postula que existe uma ordem unidimensional dos saberes (segundo a qual os saberes técnicos seriam uma aplicação dos saberes científicos e os saberes profissionais uma aplicação dos saberes técnicos) para pensar diversas formas de excelência e evitar que haja, de um lado, pessoas cultas e, do outro, pessoas de ofícios: este era o objetivo dos programas de grandes reformadores, após a Segunda Guerra, na França, como Langevin e Wallon, que, preocupados em escapar às ilusões de um universalismo que seria imanente ao ensino geral, tomavam ciência da divisão do trabalho para transformá-la ao ampliar o ensino profissional à cultura.

Eu diria também que, na Sociologia, e nas ciências sociais de uma maneira geral, o conhecimento não se adquire apenas por métodos científicos, mas também pelo conhecimento sensível oriundo da nossa experiência no mundo social. Portanto, deve-se pensar ao mesmo tempo com e contra ela, porque veicula preconceitos que resultam das nossas predeterminações.

Aprendi muito no Brasil, com as nossas trocas. Costumo dizer que esse país parece ser uma espécie de laboratório social para observar ao vivo as transformações vigentes. Não tenho tido tempo nem meios para fazer isso. Apenas tentei transmitir aos mais novos esse interesse e essa obrigação de sair dos quadros europeus, de abrir o seu olhar para esses países do Sul, ricos pela sua cultura e pelas potencialidades contidas nas transformações vigentes. Acredito que Liliana Segnini, a minha homóloga na responsabilidade dos acordos Capes/Cofecub e Fapesp/CNRS, teve mais sucesso nessa transmissão do que eu mesma. Convenceu muitos docentes-pesquisadores a participar desses programas de trocas, os quais, enriquecidos por essa experiência, atuam hoje em dia no desenvolvimento da Sociologia em diversas universidades brasileiras.

\section{Nota}

1. Receber homenagens dos seus pares sempre causa sentimentos ambivalentes: há necessariamente um sentimento de satisfação imediata pelo reconhecimento recebido, 
rapidamente encoberto por dúvidas quanto à veracidade dos elogios enunciados. Para a socióloga que sou e que acredita na pesquisa, antes de tudo, como uma atividade coletiva, não é fácil se pôr na frente do palco e recorrer ao "eu" em vez do "nós". As circunstâncias a isso me levaram. Vou fazê-lo voltando sobre o meu percurso intelectual. Agradeço calorosamente a Liliana Segnini, e aos pesquisadores que a rodeiam na Universidade Estadual de Campinas (Unicamp), por terem me oferecido esse privilégio.

\section{Referências}

BOURDIEU, P. Questions de la sociologie. Paris: Minuit, 1984.

BOURDIEU, P. Science de la science et réflexivité. Paris: Collège de France, 2001.

BRAUDEL, F. Histoire et sociologie. In: GURVITCH, G. (Org.). Traité de sociologie. Paris: PUF, 1958. t. 1, p. 83-97.

CHAPOULIE, J.-M. La seconde fondation de la sociologie française, les États-Unis et la classe ouvrière. Revue Française de Sociologie, Paris, v. 32, n. 3, p. 321-364, 1991.

CHAPOULIE, J.-M. La tradition sociologique de Chicago, 1892-1961. Paris: Seuil, 2001.

CHENG, A. La Chine pense-t-elle? Paris: Collège de France; Fayard, 2008.

COLLINS, R. Is 1980s sociology in the doldrums? American Journal of Sociology, Chicago, v. 91, n. 6, p. 336-355, 1986.

DASTON, L.; GALISON, P. Objectivity. Nova York: Zone Books, 2007. (Compte-rendu dans la Revue Française de Sociologie, Paris, v. 50, n. 2, p. 431-434, 2009).

ELIAS, N. Qu'est-ce que la sociologie. La Tour d'Aigues: L'Aube, 1991. cap. 6.

GRANGER, G.G. Le probable, le possible et le virtuel. Paris: Odile Jacob, 1995.

HACKING, I. Philosophie et histoire des concepts scientifiques. Cours au Collège de France en 2003. Disponível em: < www.collège-de-france.fr >

HUGHES, E.C. Qu'y a-t-il dans un nom? In: HUGHES, E.C. Le regard sociologique: essais choisis. Paris: Ecole des Hautes Etudes en Sciences Sociales, 1996. p. 237-251.

LENCLUD, G. En sait-on plus et mieux aujourd'hui qu'hier, en anthropologie. In: WALLISER, B. (Org.). La cumulativité du savoir en sciences sociales, en hommage à JM. Berthelot. Paris: Ecole des Hautes Etudes en Sciences Sociales, 2009. p. 327-366.

NAVILLE, P. Essai sur la qualification du travail. Paris: Marcel Rivière, 1956.

PASSERON, J.C. Sociologie, bilan et perspectives. In: GODELIER, M. (Org.). Les sciences de l'homme et de la société en France: analyse et propositions pour une politique 
nouvelle; rapport au Ministre de la Recherche et de l'Industrie. Paris: La Documentation Française, 1982. p. 195-219.

PESTRE, D. Introduction aux sciences studies. Paris: La Découverte, 2006.

POLLACK, M. Paul Lazarsfeld, fondateur d'une multinationale scientifique. Actes de la Recherche en Sciences Sociales, Paris, v. 25, n. 25, p. 45-59, 1979.

REVEL, J.F. Le pied du diable: sur les formes de cumulativité en histoire. In: WALLISER, B. (Org.). La cumulativité du savoir en sciences sociales, en hommage à JM. Berthelot. Paris: Ecole des Hautes Etudes en Sciences Sociales, 2009. p. 85-111.

ROUBAN, L. L'Etat et la science: la politique de la science et de la technologie. Paris: CNRS, 1988. p. 146.

TANGUY, L. (Dir.). L'introuvable relation formation emploi: un état des recherches en France. Paris: La Documentation Française, 1986.

TANGUY, L. Le sociologue et l'expert: une analyse de cas. Sociologie du Travail, Paris, n. 3, p. 457-477, 1995.

TANGUY, L. Questions posées sur le travail du sociologue. In: POUCHET, A. Sociologies $d u$ travail: 40 ans après. Paris: Elsevier, 2001. p. 325-334.

TANGUY, L. La mise en équivalence de la formation avec l'emploi dans le $\mathrm{IV}^{\mathrm{e}}$ et $\mathrm{V}^{\mathrm{e}}$ Plans. Revue Française de Sociologie, Paris, v. 43, n. , n. 4, p. 685-709, 2002.

TANGUY, L. La fabrication d'un bien universel. In: BRUCY, G.; CAILLAUD, P.; QUENSON, E. Former pour réformer: retour sur la formation permanente (1945-2004). Paris: La Découverte, 2007. cap. 1.

TANGUY, L. La sociologie du travail en France: enquête sur le travail des sociologues, 1950-1990. Paris: La Découverte, 2011.

THUDEROZ, C. Sociologie des entreprises. Paris: La Découverte, 1996.

Recebido em 29 de fevereiro de 2012.

Aprovado em 15 de março de 2012. 